\title{
Climate change adaptation strategies in Mexico
}

\author{
J. F. Audefroy \\ Escuela Superior de Ingeniería y Arquitectura (ESIA-Tecamachalco), \\ National Polytechnic Institute (IPN), Mexico
}

\begin{abstract}
This paper is about the introduction of adaptation strategies as part of the decisionmaking process of state and municipal authorities, local communities and the private sector. Many aspects of adaptation can only be implemented through the actions of state and municipal authorities; in other words, facilitate, promote, allow, support and control. Collaboration among the various actors is almost always a success factor, although it does not always exist. Current financial, regulatory and environmental systems offer little leeway for adaptation. For example, resettling, abandoning damaged buildings, and reconstructing in the same location are all actions taken by state authorities with scant regard for adaptation to climate change. Nor are development and planning priorities such as land-use, zoning regulations and infrastructure supply aligned with the objectives of adaptation. A real disconnect exists between development objectives and adaptation to climate change.

Local authorities' ability to work effectively on their own or in conjunction with others is clearly limited by insufficient funds and technical knowledge, and by a lack of information and leadership.

Keyword: adaptation, climate change, strategies, housing, Mexico.
\end{abstract}

\section{Introduction: climate change on Mexico's national agenda}

The issue of climate change is not yet part of the national debate. The major media companies broadcast disjointed information, separating causes from effects: reporting focuses on disasters (invariably described as "natural") and their effects, but causes are hardly mentioned, apart from global warming. At the same time, the mainstream media address climate change as if it were a global phenomenon, even though we know that its effects are highly differentiated by region and country. 
Mexico contributes $1.5 \%$ of global greenhouse gas emissions (GHGs), and ranks 13 among the world's largest emitters, thus confirming its responsibility.

The United Nations Framework Convention on Climate Change (UNFCC) was signed by the Mexican government in 1992 and was later ratified by the senate in 1993. It was only seven years later that the issue of climate change was placed on the government's agenda. In 2007, the issue was first mentioned in the country's 2007-2012 National Development Plan (PND), with just a few action lines specifically seeking to prevent and mitigate GHG emissions and to adapt to the effects of climate change. The 2009-2012 Special Climate Change Program establishes short-term GHG emission-reduction commitments. We are still far from achieving housing policies that specifically address climate change.

In 2005, Mexico joined the Inter-Ministerial Committee on Climate Change to formulate the National Climate Change Strategy in 2007 and the National Climate Change Program. It was only in 2010 that some of the state programs were rolled out: the first two were in Veracruz and the Federal District, and a further eight are currently under development. However, the State Climate Change Programs pay insufficient regard to the state risk atlases.

The Mexican Government's 2009-2012 National Climate Change Strategy proposes scenarios in different issues and sectors, including for urban areas and human settlements.

Public climate change policies have been designed amid a general lack of awareness about the climate issue which has so far been the preserve of specialists in the scientific fields: meteorologists, climatologists, etc. In fact, few connections exist between those drawing up public policies and scientists. The programs that have been designed around climate change have essentially been based on reports by the International Panel on Climate Change, IPCC, whose conclusions and recommendations are on a global level making it highly risky to apply them on a national or regional level. Furthermore, a disconnect exists between the risk atlases, the CENAPRED (National Disaster Prevention Center), civil protection authorities, and the results issued by the IPCC and scientists in Mexico. No synthesis has yet been made between the various sources of information from these different agencies and instruments. Who is going to do this, and at what level?

Mexico's federal institutions are aware of the global environmental and climatic problem, and they also have a discourse on its possible causes and impacts, but this is insufficient for the local institutions, the general public and civil society to take part in the debates. No instrument exists for civil society to join the national debate on the environment and climate change. The general public is unaware of the extent of the problem. However, in rural communities, which bear the full brunt of the effects and frequency of the impacts of climate change, there is a greater level of awareness of the problem than in urban areas, where the effects (floods, mudslides, etc.) are not yet perceived to be the effects of environmental degradation and climate change. It is not yet clearly felt that the risks have been socially constructed by different actors and policies.

Reconstruction programs are considered as social housing programs for lowincome sectors, whereas they should in fact be habitat-oriented programs for adaptation to the effects of climate change, designed jointly with inhabitants, by 
specialists, and not only by construction companies that do nothing to help the situation.

The media largely ignore the technical and scientific debate, and hardly any connection exists between discussions on the implications of climate change and national life. Organized rural communities, neighborhoods, and local urban associations are excluded from national and international discussions. Nationally, in the case of Mexico at least, no space exists where the climate change issue can be debated between the government and civil society organizations. However, this space does exist for human rights' issues.

\section{Institutional adaptation and reconstruction practices}

Actions taken by the Mexican government for adaptation to the effects of climate change are relatively recent and have arisen from international commitments undertaken by Mexico by forming and ratifying agreements drawn up as part of international platforms convened by the United Nations and the COPs since 1995.

The recent IPCC report, Climate Change 2014: Impacts, Adaptation and Vulnerability [1], and in particular its chapter 8, provides some interesting examples of adaptation strategies to reduce the effects of climate change in rural areas.

The report specifies that, in 2008, over half the world's population was living in urban areas, and this figure is rising. At the Mexican level this information shows that the country's urban population is $76.8 \%$ (INEGI [2]). In other words, higher than the global average. The growing urban population can generate new, previously unidentified risk patterns. Historical records of disasters are not directly related to urban settlements, and shifting populations are not considered in historical studies of hydrometeorological events. The concentration of the urban population considerably increases exposure to risks and threats, and the area vulnerable to this risk is increasing in the same way as the population. Exposure and physical and social vulnerability is linked to extreme climatic conditions (storms and hurricanes, floods, and landslides). This is extremely relevant to climate change adaptation, given the rising frequency and intensity of potentially dangerous meteorological phenomena associated to climate change, as we have observed on a local scale.

The municipal governments which have developed adaptation policies recognize the importance of having a department specifically assigned to this area, in order to compile the relevant information and encourage the involvement of different sectors and actors. Unfortunately, this is not the case in many municipalities.

Policies and incentives must be combined if they are to work coherently through different levels of authority (within different areas of government) in order to be able to define and construct an effective adaptation. If it is not possible to ensure a consistent coordination and integration of risk management, decisions may be taken that exacerbate the vulnerability of urban groups, infrastructure, and natural systems (such as rivers), even where an adaptation policy does exist (Revi [1]). 
The local government's capacity is important, as are the institutions that help coordinate between different actors in order to incorporate the adaptation measures within national targets and policies. The local government can also promote the prevention of climate change risks and help create a shared vision for the future.

Another problem is the tension between neoliberal economic policies and the increasing needs of low-income groups whose resistance to climate change will depend on the quality of infrastructure and urban services. The local and state governments' lack of focus on the most vulnerable populations prevents the implementation of adaptation processes. For example, social housing policies that benefit construction companies prevent the poorest sectors of society from accessing government programs and therefore they have to find places to live for themselves - either on land exposed to risks or not. Today's housing policy lacks instruments for catering to the entire population (Ortiz [3]).

For adaptation to be successful, it must be integrated within urban planning and land-use regulation, and within legal frameworks. However, land at risk generally means land where there has never been urban planning but is the result of people "invading" urban land after having been excluded from institutional programs. This IPCC recommendation (Climate Change 2014: Impacts, Adaptation and Vulnerability) is merely theoretical since it is not implemented in practice.

The high-vulnerability of conditions linked to most people's reduced capacity to cope with the repercussions of climate change complicate both mitigation and adaptation strategies.

Adaptation measures are formulated in the National Strategy on a very general basis. For example, the management of hydrometeorological risks proposes riverbasin management in order to lessen risks. This is the usual approach. However, what is important is river-basin management in cases of emergencies or intense hydrometeorological events such as in 2007 in Tabasco where it appears that the dams were not optimally used. The water bodies must always conserve a storage volume in order to cope with cases of extreme precipitation events. Another proposal is to rescue traditional techniques for handling natural resources, but nowhere is it specified how water policies are going to be modified in order to allow or encourage the use of these traditional technologies. The very general proposals do not make it possible to assess how they are related to exposure to the specific risk and vulnerability of each region or river basin in terms of the management of risk and water resources.

In coastal areas, such as in the Yucatán, proposed adaptation processes intend to tackle the expected rise in sea levels by relocating populations, and through actions designed to reorient the fishing and tourism industries. However, these proposals do not take into account any adaptation of the fishermen's habitat in response to the rising sea levels, even though precedents exist around the world of fishing communities living on houses built on stilts. This would help limit environmental migration, and require less investment than would otherwise be required by displacing communities. In the tourism sector, one can envisage tourism developments raised on stilts that would prevent the problems associated with workers developing new productive activities. 


\section{The role of community organizations in adaptation}

Involving citizens, civil society, the private sector and other actors and partners is all essential for science to be able to tackle a problem of such inherent uncertainty and complexity as climate change. Actions taken by people and communities to deal with environmental degradation and the effects of climate variability are not a new phenomenon and date back centuries. But they are always measures taken to address a real threat. Other planned actions are the result of a set of skills, capacities or knowledge of a community, as is the case with the fishermen of San Felipe in the Yucatán.

In a well-run city or municipality, local governments and community groups provide mutual support, providing and sharing information and resources to protect the environment and to ensure civil protection, key elements for adaptation.

In informal settlements with poor infrastructure and services, the population's participation is key in assessing community risk and the local ability for adaptation is partly based on knowledge of the area, for example traditional Maya housing designed to cope with hurricanes. In many municipalities, where infrastructure is incomplete and family income limited, community organizations can offer the possibility of adaptation to face future risks. Several studies have reported on the depth of knowledge and skills of local populations aimed at reducing risks, exposure and vulnerability (see Dodman and Mitlin [4]; Zarate [5]; Wilkinson [6]). For many homes in low-income neighborhoods exposed to floods or hurricanes, adaptation is their only means of responding to threats and they are very used to dealing with climatic threats. Some try to mitigate dangers or reduce exposure, for example, by installing ventilation and roof covers to lower the high temperatures; erecting barriers to prevent floodwater entering their homes; placing food baskets on top of furniture; raising up fridges on bricks and sometimes temporarily moving to safer places. These are important short-term adaptive measures, and similar strategies are employed in many low-income neighborhoods. However, they do not create the ability to adapt to extreme future risks.

A number of limitations face low-income families when it comes to adaptation. Families do not trust in the authorities, even when there are early warnings. They also doubt that their property will be safe if they abandon it and they are afraid for their own physical safety in shelters. These are all factors that dissuade people from evacuating and limit their adaptive capacity.

Families in rental accommodation or who do not own land are often the most vulnerable and exposed to risks, because they are also very reluctant to invest in home improvements and less willing to invest time in community initiatives. We could observe this in some traditional houses along the Yucatán coast, which have seen very little maintenance and suffered significant hurricane damage.

It is grossly unrealistic to attempt to pass on responsibility for this entire adaptation process to communities because barriers exist that they cannot overcome. For example, communities can construct and maintain local water sources, drain off gray water and toilets, but they cannot provide mains water supply or drainage or collectively treat water. However, at a family level, they can 
install domestic gray water treatment systems, and dry toilets without requiring a drainage network. Our fieldwork in the state of Yucatán indicates the need to link into community support networks and/or the local government for a more effective adaptation at a community level.

In Mexico and Latin America, there have been various experiences in which adaptation is also community-based. Communities which have close connections to state institutions can improve their adaptive capacity, however this does not mean that new housing and house improvement programs lessen vulnerability to climate events in one fell swoop. As we have seen in the case of San Felipe, housing programs have not reduced vulnerability to the risk of flooding. The immediate effect of these programs is the incorporation of low-income families into the "formal" sector of the city and this means, for the State, a reduction in vulnerability and also, in the long term, strategic investments and adaptation through schools, health clinics and infrastructure.

In other cases, micro-financing programs can help adaptation through various financial instruments such as micro-savings, micro-loans and micro-insurance services. These programs were available in the case of the Yucatán, but would perhaps have been more efficient for housing improvements, limiting the vulnerability of housing stock to floods and hurricanes. Indeed, these plans have mostly been applied in rural areas and generally have benefitted those with some property and therefore not all families have been able to take advantage of these programs.

One of the limitations of the micro-financing program for adaptation is that, on the whole, it provides loans to individuals or families and therefore it isn't easy to use them to fund collective investments such as, for example, sanitation works, landslide mitigation, storm-water drainage or rainwater harvesting systems. Von Ritter and Black-Layne [7] have explored the possible role of micro-financing and crowdfunding to help support local climate change initiatives, such as small-scale decentralized energy solutions, "climate-proof" houses; they also suggest that the new Green Climate Fund could support this activity through its private sector window.

\section{Toward a housing and habitat policy adapted to climate change}

Disasters have a significant financial impact for the State, the private insurance sector and for people themselves and in the absence of a housing policy adapted to climate change, this financial impact tends to increase. The example of the financial impact of Hurricane Isidore in 2002 in the Yucatán shows the financial participation of the different sectors of society (public, private and communities). The public sector at the federal and state levels contributed $\$ 1,746,200.00$ pesos. Fund for Natural Disasters (FONDEN) resources represented $20.12 \%$ of the total cost of damaged caused by this weather event. The insurance sector contributed $\$ 2.97$ billion pesos, representing $45.5 \%$ of the total damage. This statistic is notable as it means that the insurance sector provided double the resources provided by the federal and state governments combined for repairs and 
reconstruction. The total contributions from the FONDEN and the insurance sector accounted for $65.62 \%$ of the total losses, implying that the remaining $34.38 \%$ had to be covered by the victims themselves, and with donations or other types of additional financing.

\subsection{What would a housing policy adapted to climate change look like?}

Poverty-related challenges and trends can be found in both urban and rural contexts. Poverty is a determining factor in the vulnerability to climate change, precisely due to the quality and location of housing. Lower-income groups are most affected due to the combination of higher exposure to climatic threats (for example, those living in more precarious housing in unsafe and/or remote locations), less capacity to deal with threats (for example, the lack of assets and insurance), a weaker adaptive capacity, less public resources available to help them recover, and less legal protection, precisely because they are those who own less property. Reduction in poverty and reduction in vulnerability are closely intertwined. Only public policies are able to achieve these objectives.

Here we must challenge some myths, such as the famous neoliberal notion that climate change adaptation in rural and urban areas often consists of strategies and activities already implemented under the heading of "good development". In rural areas, for example, the sustainable management of natural resources and improved market access can be key in the construction of adaptive capacity (OECD [8]). Market access does not reduce either vulnerability or poverty. What can help reduce vulnerability is a housing policy that includes the entire population and not just $40 \%$ - its current level in Mexico. Poverty reduction is not only brought about through social policies but with salary adjustments, especially those at the lowest end of the scale. It's time to make "structural adjustments" but this time to the market, and no longer to the triad of health, education and housing.

Mexico's Ministry of Social Development (SEDESOL), through its Department for Urban Development and Land-Use Planning, drew up a document called "A Municipal Guide for Response to Climate Change, with an Emphasis of Urban Development Land-Use Planning" that "seeks to strengthen policies of insuring manufacturing infrastructure, buildings and houses; modifying exposure to risk through projects to increase protection or even the relocation of at-risk human settlements, updating the legal and institutional framework of local public management, which spans everything from construction regulations to building codes, even a reform to the local public administration in order to ensure a suitable and timely response to the climate-change related disasters" (CIDOC [9]). This praiseworthy initiative does not contemplate changes to housing policy. Furthermore, the Program for Risk Prevention in Human Settlements (PRAH), a project being promoted by SEDESOL in order to support local governments in taking measures that may reduce the threats for the at-risk population and directing housing developments toward more suitable zones, has had little impact so far. At a national level, many municipalities in Mexico still lack risk atlases. As of 2013, 177 risk atlases have been created since the beginning of the PRAH for the 2,456 municipal districts in Mexico. 
The Program does not specify how these preventive measures could be put into practice. For example, discouraging land-use in high risk areas is not achieved with risk atlases that are aimed at getting the same local authorities to take them into account when granting building permits or at real estate developers who frequently ignore them. This program is a part of the current housing policy, which only offers housing to between 30 and $40 \%$ of the population.

\subsection{Mexico's current housing policy}

The new National Housing Policy (PNV) in the current administration is based on four strategies: strengthening institutional coordination; using finance for housing to guide urban development; reducing the shortfall in housing; and improving measures to help in house improvement actions (CIDOC [9]). The second aspect involves moving towards a sustainable urban development model. The federal government's credits and subsidies will be re-directed towards encouraging planned urban growth. Vertical housing programs will be promoted. Since 2014, the operating rules of subsidy programs have placed more emphasis on location. These aspects of housing policy point towards better urban development, improved use of urban land, yet they still do not take into account some strategic aspects related to climatic variability in Mexico. Furthermore, the 2013-2018 National Development Plan forecast reveals that one sector of the population in particular is not being looked after: the sector of society not enrolled in the social security program or catered to by any of the housing institutions, representing $73 \%$ of the country's requirement yet which receives only $30 \%$ total financing for housing. Currently it is estimated that 2.8 million houses exist across Mexico that need to be replaced and that 11.8 million require some type of improvement or extension. These data give an idea of the high level of vulnerability of the real estate stock in Mexico.

Real changes are therefore required in the country's current housing policy, so that the entire population has access to dignified and safe housing, in preparation for the impact of climate change. Some gaps exist that could form part of the solution, such as, for example, the Social Production of Housing, in reducing vulnerability.

\subsection{The social production of housing}

Since the Social Production of Housing (PSV) was included in the 2006 Housing Law, some important progress has been made in implementation and financing. PSV is linked to the rural communities, urban neighborhoods and self-managing housing complexes actively involved in management. This can make significant contributions to strengthening the social fabric, improving security and reducing vulnerability by targeting a population that has remained excluded from programs on the market (CIDOC [9]).

"As shown in some self-management experiences during the reconstruction of Mexico City following the 1985 earthquakes, and 
numerous specific instances in central areas by NGOs and social organizations in the $1960 \mathrm{~s}$, it is possible to rehabilitate, subdivide and renovate existing houses through processes of social production which, when placed on a larger scale, can help redensify well-located and wellserved zones that are currently being abandoned and left in disrepair." (CIDOC, Enrique Ortiz, HIC-AL, 2013).

It is remarkable that 7 of the 11 social developers accredited by the National Housing Commission (CONAVI), undertook a total of over 8,000 actions (2012) through participative processes that included an integral (social and technical) advisory service, and in many cases were jointly supported by several actors. Although the production and social habitat management processes do not create profitability for capital invested due to their inherently non-profitable nature, they do become profitable in terms of improved civic culture, social responsibility, social fabric, social inclusion and cohesiveness. Ultimately it is a form of housing production that could be used in reconstruction programs after disasters or traditional housing improvement programs.

\section{Conclusions: climate change impacts are also the outcome of social construction of risks}

This research has led to findings that challenge some myths:

(a) The social construction of risk is both the result of urban and social policies, and of processes by which human intervention in the environment leads to the creation of new physical events and phenomena as well as socio-natural threats. The social construction of risk is a factor that adds multidimensional vulnerability of goods and of people. The lack of municipal risk atlases is one form of social construction of risk since the necessary information is lacking with which to design urban development plans. Regular or irregular exposed human settlements in risk zones also participate in the construction risk. Management of river basins, rivers and dams can also contribute to construction risks. More knowledge is therefore required to manage river basins in extreme situations, as well as to handle the intensity, recurrence and patterns of extreme events. Perhaps we also need another type of map that shows both natural and anthropogenic threats at a local or regional level.

(b) Multidimensional-economic, social, physical cultural-vulnerability explains many of the impacts of extreme events attributed to the effects of climate change. In each of the case studies we have found high vulnerability to climate variability. Unfortunately, little research has been undertaken to analyze the changing patterns of vulnerability and exposure and their repercussions on adaptation. In this study, we have tried to insist on the key role of vulnerability, always looking at the physical and socioeconomic of populations and goods exposed to climate variability. We have noted radical solutions to reduce vulnerability, such as the displacement of communities, which ultimately have simply displaced problems and risks. As a means of reducing vulnerability and helping award adaptation, changing habitat patterns also proved unsatisfactory 
because of its negative impacts on local culture and heritage, as found in the case of the Yucatán. Reducing vulnerability is achievable through policies, plans and programs in a number of areas: housing improvement programs, poverty reduction programs, ecological rescue plans, and policies which involve the participation various stakeholders.

(c) Stakeholders and their role in adapting to the effects of climate change: We have seen the importance of the role played by different actors in terms of adapting to the effects of climate change; institutional social and community stakeholders have been instrumental in their actions relating to adaptation to climate change. However, they must work in collaboration, the best experiences being those cases where local authorities and social organizations have worked together. Institutional and social actors can play a role in prevention, adaptation and in emergencies. Traditional practices are one form of adaptation as we have noted in the Yucatán's coastal communities, for example. The rituals and customs of observing the weather are one such forms of adaptation that have only recently been recognized in the scientific media.

(d) Disasters from the climate change perspective: We have tried to compile issues such as Disaster Risk Reduction and Climate Change. This false separation of two so such clearly related issues, as Cardona [10] has noted, for various historical and institutional reasons, must be resolved if we wish to make progress in both areas of risk.

(e) Populations exposed to climatic variability have always had to deal with extreme events through historical strategies of prevention, mitigation and adaptation. This knowledge is very helpful in designing plans to adapt to climate change, but unfortunately policies and programs overlook this highly valuable source of knowledge for decision-makers.

(f) Not all exposures and vulnerabilities are poverty related. Poverty, just like climate change, does not explain everything. Although poverty has a strong bearing on social and economic vulnerability, physical and institutional vulnerabilities exist which are more relevant than poverty when it comes to designing policies.

(g) Climate change on its own does not explain all the disasters that happened in recent decades. This study has shown that some anthropogenic elements play a major role in disastrous effects, such as poverty, vulnerabilities, environmental destruction, urban and housing policies, and in some cases the lack of development.

\section{Acknowledgements}

Funding for this study was provided by the Department of Research and Postgraduate Studies of the National Polytechnic Institute (IPN), Mexico (SIP N ${ }^{\circ}$ 20151000) and COFAA. 


\section{References}

[1] Revi, A.; Satterthwaite, D.; Aragón-Durand, F.; Corfee-Morlot, J.; B.R. Kiunsi, R.; Pelling, M.; Roberts, D.; Solecki, W., Chapter 8: Urban areas, in IPCC, Climate Change 2014: Impacts, Adaptation and Vulnerability, Contribution of Working Group II to the $5^{\text {th }}$ Assessment Report of the Intergovernmental Panel on Climate Change, Cambridge University Press (n.p.), 113p., 2014.

[2] INEGI, Censo de Población y Vivienda, México, 2010.

[3] Ortiz, Enrique, "Housing for All: Challenges for the World's Governments", in Environmental Impact Assessment, Review 16. Elsevier Science Inc. Nueva York, NY. pp. 439-442, 1996.

[4] Dodman, D. \& Mitlin, D., Challenges for community-based adaptation: discovering the potential for transformation, in: Journal of International Development, 25(5), Chichester, pp. 640-659, 2011.

[5] Zarate, María Lorena, Construyendo otros mundos posibles, HIC-ALMisereor, Mexico, p. 14, 2012.

[6] Wilkinson, Emily, La gestión del riesgo en la Península de Yucatán, in: Medio Ambiente y Urbanización, April 2013, N78, IIED-AL, BuenosAires, pp. 63-90, 2013.

[7] Von Ritter, K.; Black-Layne, D., Crowdfunding for Climate Change: A new source of finance for climate action at the local level, ECBI policy brief European Capacity Building Initiative, Oxford, p. 18., 2013.

[8] OECD, Integrating Climate Change Adaptation into Development Cooperation, Policy guidance, OECD Publishing, Paris, 197pp., 2009.

[9] CIDOC, SHF, Estado Actual de la Vivienda 2013, Mexico, 161pp., 2013.

[10] Cardona, O. et al., Entendimiento y gestión de riesgo asociado a las amenazas naturales: un enfoque cientifico integral para América Latina y el Caribe, Volumen 2, ICSU-LAC-CONACYT, Mexico, 87pp., 2010. 